\title{
A Dual Function Activity-Dependent, Muscle-Specific Enhancer from Rat Nicotinic Acetylcholine Receptor $\delta$-Subunit Gene
}

\author{
Wade Walke, Guozhi Xiao, and Daniel Goldman* \\ Mental Health Research Institute and Department of Biological Chemistry, The University of Michigan, \\ Ann Arbor, Michigan 48109
}

\section{SUMMARY}

Nicotinic acetylcholine receptors ( $\mathrm{nAChR}$ ) mediate communication between nerve and muscle. The expression of these receptors increases dramatically during muscle development when myoblasts are fusing into multinucleated myotubes. The molecular mechanisms mediating this muscle developmental stage specific expression are not well understood. We report here the identification of nAChR $\delta$-subunit promoter DNA sequences that differentially interact with nuclear proteins isolated from myoblasts, myotubes, and nonmuscle cells. The functional role these sequences play in mediating musclespecific expression was explored using mutagenesis and enhancer assays. These studies resulted in the identifi-

\section{INTRODUCTION}

The muscle nicotinic acetylcholine receptor ( $\mathrm{nAChR}$ ) is a pentameric integral membrane protein that functions as a ligand-gated ion channel. It is composed of four different subunits with a stoichiometry of $\alpha_{2} \beta \gamma(\varepsilon) \delta$. Acetylcholine binds to the $\alpha$ subunits to cause a conformational change in the receptor that results in ion flow across the membrane. In muscle this conductance activates voltage-dependent sodium channels ultimately resulting in muscle contraction.

In adult skeletal muscle nAChRs are localized

Received April 2, 1996; accepted June 17, 1996

Journal of Neurobiology, Vol. 31, No. 3, pp. 359-369 (1996)

(C) 1996 John Wiley \& Sons, Inc. CCC 0022-3034/96/030359-11

* To whom correspondence should be addressed (e-mail: neuroman@umich.edu). cation of a 47-bp muscle-specific enhancer that mediates increased expression of the $\mathrm{nAChR} \delta$-subunit gene during myotube formation. This enhancer contains an E-box and an element with similarity to the $S V 40$ core enhancer (SVCE). Point mutations throughout this 47-bp enhancer showed that the E-box and the SVCE sequence are both necessary for conferring muscle-specific expression onto a heterologous promoter. Interestingly, this same DNA sequence also functions as an activity-dependent enhancer. (C) 1996 John Wiley \& Sons, lnc.

Keywords: muscle-specific enhancer, activity-dependent enhancer, muscle development, gene expression, nicotinic acetylcholine receptor.

to the neuromuscular junction. However, muscle denervation results in a large increase in $\mathrm{nAChR}$ expression throughout the muscle fiber. Similar to the increase in expression following muscle denervation, nAChRs are also induced during muscle development when myoblasts fuse into multinucleated myotubes (Bevan and Steinbach, 1977). These increases in receptor protein are largely accounted for by changes in nAChR subunit gene expression (Buonanno and Merlie, 1986; Tsay and Schmidt, 1989). It has been suggested that the mechanisms mediating developmental induction of $\mathrm{nAChR}$ gene expression may be similar to those mediating induction of these genes following muscle denervation (Simon and Burden, 1993). Consistent with this idea is the identification of myogenic factor binding E-box sequences (CANNTG) that participate in both muscle developmental stage specific and activity-dependent expression of nAChR genes (Berberich et al., 1993; Bessereau et 
al., 1993, 1994; Numberger et al., 1991; Piette et al., 1990; Prody and Merlie, 1991; Wang et al., 1988; Tang et al., 1994; Su et al., 1995). However, because many muscle-specific genes contain these E-boxes it is likely that other elements are also necessary for mediating activity-dependent control of gene expression and perhaps developmental stage specific expression. We have begun to identify the elements mediating activity-dependent expression of the nAChR $\delta$-subunit gene (Walke et al., 1996). In this report we focus on DNA elements mediating developmental stage specific expression of the $\delta$ gene.

Among the rodent $\mathrm{nAChR}$ subunit genes, that encoding the $\delta$ subunit is unique in that it requires a region of DNA containing a single E-box for muscle-specific expression ( Baldwin and Burden, 1988; Chahine et al., 1992). Similar to other characterized E-boxes, the mouse $\delta$-gene's E-box contributes to high level $\delta$-subunit gene expression in myotubes. However, unique to this E-box is its ability to also suppress $\delta$-subunit gene expression in myoblasts and other nonmuscle cells (Simon and Burden, 1993). Another unique feature of this gene is its near wild-type expression in myogenin deficient mice (Hasty et al., 1993). In contrast the nAChR $\alpha$ gene, along with other muscle-specific genes, is shut off in these animals. These results suggest a unique mode of regulation of the $\delta$-subunit gene in muscle and nonmuscle cells and underscore the importance of characterizing the mechanisms controlling its muscle-specific expression.

In order to identify mechanisms contributing to muscle-specific expression of the $\delta$-subunit gene, it is necessary to define the DNA elements that are involved in this specific expression pattern. Although the E-box is certainly one of these elements, we show here that it is not sufficient for conferring this pattern of expression onto a heterologous promoter. To identify additional elements contributing to the muscle-specific expression of this gene we used methylation interference assays to identify sequences within the rat $\delta$-subunit gene's promoter that differentially bind muscle- and nonmuscle-derived nuclear proteins. These regions of DNA were then tested in functional assays to determine their role in mediating muscle-specific gene expression. These studies identified a 47-bp muscle-specific enhancer of the rat $\delta$-subunit gene. This enhancer contains an E-box and a sequence with similarity to the SV40 core enhancer (SVCE) (Khoury and Gruss, 1983), both of which are necessary for muscle-specific enhancer activity. This enhancer was recently shown to also confer muscle activity-de- pendent regulated expression onto a heterologous promoter (Walke et al., 1996).

\section{MATERIALS AND METHODS}

\section{Plasmids}

For the enhancer experiments a minimal enkephalin promoter construct (MEK pXP2) was made by placing a 135-bp fragment of the enkaphalin promoter (Comb et al., 1986), extending from nucleotides -72 to +60 relative to the transcriptional start site, in the Sma I and filled in $\mathrm{Bgl}$ II sites of the pXP2 vector driving luciferase expression (Nordeen, 1988). Short oligonucleotides spanning the sequences from the $\delta$ promoter (Chahine et al., $1992)$ as indicated in Figures $3-5(\delta-106 /-72, \delta-81 /$ $-32, \delta-47 /-1, \delta-25 /+10$ ) were synthesized with a $B a m \mathrm{HI}$ restriction enzyme site included on the $5^{\prime}$ end of the oligo and a $B g I I I$ restriction enzyme site included on the $3^{\prime}$ end. These oligos were then placed in the BamHI site of the MEK pXP2 construct in both orientations. The oligos were also placed into the promoterless $\mathrm{pXP} 2$ plasmid to test for promoter activity, and in addition subcloned into BSSK $(+)$ for sequence determination.

For the mutation and deletion studies on the $\delta$ promoter we used the pXP $\delta 550 / 4$ construct described previously (Chahine et al., 1992), containing sequences -550 to +11 relative to the transcriptional start site. Scanner-linker mutations ( $\mathrm{s} / \mathrm{m}$ ) were generated by doing a series of $5^{\prime}$ and $3^{\prime}$ deletions on this construct using exonuclease III. These deleted DNAs were sequenced in order to define their $5^{\prime}$ and $3^{\prime}$ ends. Deletions that had $3^{\prime}$ ends exactly 17 bp upstream of an appropriate $5^{\prime}$ deletion were ligated with a 17-bp linker inserted in between. One exception was $\delta-550 \mathrm{slm}-44 /-29$, which only has a 16-bp deletion between ends, with a 17-bp linker inserted. The sequence of the linker is CAGATCTCGAGCTCCAC. This linker contains three unique restriction sites: $B g l \mathrm{II}, X h o \mathrm{I}$, and $\mathrm{SaC}$ I. These scanner-linker mutations were also assayed in a $\delta$-promoter construct whose $5^{\prime}$ end was at position -119 . These constructs were generated by polymerase chain reaction (PCR) amplification using an oligonucleotide with a $5^{\prime}$ end at -119 and another oligonucleotide complimentary to plasmid sequence flanking the $3^{\prime}$ end of the $\delta$-promoter insert. The PCR fragment was then cut with HindIII and cloned in to the Sma I/ HindIII sites of BSSK ( +) for sequencing and subsequently cut with BamHI/HindIII and subcloned into the BamHI/HindIII sites of the pXPI vector. Internal deletions of the $\delta$ promoter were created by cutting the various scanner-linker mutants with Xho I, which cuts in the linker, and HindIII to remove the $3^{\prime}$ ends, and then ligating different $3^{\prime}$ ends with different $5^{\prime}$ ends as indicated in Figure 5. All mutations and deletions generated were also subcloned into $\operatorname{BSSK}(+)$ for sequence analysis.

MCKCAT and SV2CAT constructs were used to nor- 
malize for transfection efficiency and were described previously (Chahine et al., 1992; Walke et al., 1994).

\section{Cell Culture and Transfections}

For the transient transfection assays, $60-\mathrm{mm}$ dishes were seeded with either $\mathrm{C} 2 \mathrm{C} 12$ myoblasts or NIH3T3 cells at a density of $1 \times 10^{4}$ cells per dish. $\mathrm{C} 2 \mathrm{C} 12$ cells were grown in Dulbeccos's modified Eagle's medium (DMEM) supplemented with $20 \%$ fetal bovine serum (FBS) and antibiotics/antimycotic. NIH3T3 cells were grown in DMEM supplemented with 10\% FBS and antibiotics/ antimycotic. All cells were grown in a humidified incubator at $37^{\circ} \mathrm{C}$ in $5 \% \mathrm{CO}_{2}$. Cells were transfected $24 \mathrm{~h}$ after plating using the calcium phosphate method previously described (Wigler et al., 1979) with the following modifications. In all experiments $10 \mu \mathrm{g}$ of $\delta$-promoter constructs were cotransfected with $20 \mu \mathrm{g}$ of either SV2CAT or MEKCAT vector. The CAT vector and subsequent CAT assays were used to normalize for variations in transfection efficiency between plates. In short, our procedure was to wash cells once with DMEM without serum and then place $3 \mathrm{~mL}$ of DMEM without serum onto plates. DNA-calcium phosphate precipitates $(0.5 \mathrm{~mL})$ were then added to cells dropwise and allowed to incubate with cells for $1 \mathrm{~h}$. Cells were then glycerol shocked for $2 \mathrm{~min}$ with a solution of $1 \times \mathrm{HBS}(140 \mathrm{~m} \mathrm{M} \mathrm{NaCl}$, $23 \mathrm{~m} M$ HEPES, $\mathrm{pH} 7.1$, and $0.75 \mathrm{~m} \mathrm{M} \mathrm{Na} \mathrm{HPO}_{4}$ ), $15 \%$ glycerol, and fed fresh growth media. The media was changed $12 \mathrm{~h}$ after glycerol shock and daily thereafter. To induce fusion of myoblasts media was changed to DMEM containing $5 \%$ horse serum at $12 \mathrm{~h}$ after glycerol shock. Cells were harvested for luciferase and CAT assays 2-3 days after glycerol shock by lysis in $200 \mu \mathrm{L}$ of $0.25 \mathrm{M}$ Tris-Cl ( $\mathrm{pH} 7.5$ ), $1 \%$ Triton-X. Assays were performed as previously described (Brasier et al., 1989; Neumann et al., 1987). All transfections were performed in triplicate and repeated at least twice.

\section{Dimethylsulfate (DMS) DNA Footprinting}

DNA probes were made from a $\delta$-promoter clone containing 102 bp upstream of the transcriptional start site. One end of the probe was ${ }^{32} \mathrm{P}$ labeled by Klenow fill-in reaction, isolated on a polyacrylamide gel, eluted, and purified by phenol:chloroform:isoamyl alcohol (25:24: 1) extraction and ethanol precipitation. Crude nuclear extracts were prepared by the method of Dignam et al. (1983). In some experiments crude nuclear extracts were partially purified by DEAE Sephadex column fractionation and ammonium sulfate precipitation as follows. Thirty milligrams of crude nuclear protein was added to a DEAE Sephadex A-50 column. The column was washed with $150 \mathrm{~mL}$ of buffer A $[20 \mathrm{~m} M$ HEPES, (pH 7.9 at $4^{\circ} \mathrm{C}$ ), 20\% glycerol, $0.2 \mathrm{~m} M$ EDTA, $0.2 \mathrm{~m} M$ PMSF, $0.5 \mathrm{~m} M$ dithiothreilol (DTT) $0.1 M \mathrm{NaCl}$ ]. The column flow through containing the nuclear proteins was adjusted to $33 \%$ ammonium sulfate and then slowly mixed for $60 \mathrm{~min}$ at $4^{\circ} \mathrm{C}$. Precipitated proteins were isolated by centrifugation in a $\mathrm{Ti} 45$ rotor (Beckman) at $18,000 \mathrm{rpm}$ for $30 \mathrm{~min}$ at $4^{\circ} \mathrm{C}$. The pellet was then disolved in buffer $\mathrm{A}$ and dialyzed overnight at $4^{\circ} \mathrm{C}$ against 100 volumes of buffer $A$.

DNA-protein binding reactions and DMS footprinting were performed by incubating $12.5-200 \mu \mathrm{g}$ of protein from nuclear extracts in $125 \mu \mathrm{L}$ of binding buffer [25 m $M$ HEPES, pH 7.9, $100 \mathrm{~m} M \mathrm{NaCl}, 10 \%$ glycerol, $1 \mathrm{mg} / \mathrm{mL}$ BSA, $0.5 \mathrm{~m} M$ DTT, $0.2 \mathrm{~m} M$ PMSF, $50 \mu \mathrm{g} /$ $\mathrm{mL}$ poly $(\mathrm{dI}-\mathrm{dC})]$ with $20,000 \mathrm{cpm}$ of labeled probe $(\sim 0.1-0.2 \mathrm{ng})$ for $20 \mathrm{~min}$ at room temperature. After the binding reaction, samples were treated with $75 \mu \mathrm{L}$ of DMS diluted 1:200 in DMS reaction buffer $(50 \mathrm{~m} \mathrm{M}$ sodium cacodylate, $\mathrm{pH} 8.0,1 \mathrm{~m} M$ EDTA) for 2 minutes at $25^{\circ} \mathrm{C}$. DMS reaction was terminated with DMS stop solution ( $1.5 \mathrm{~m} M$ sodium acetate, $\mathrm{pH} 7.0,1 M \beta$-mercaptoethanol, $250 \mu \mathrm{g} / \mathrm{mL}$ yeast tRNA). Samples were then phenol/chloroform extracted and precipitated with ethanol. Strand cleavage at methylated guanine residues was then carried out as outlined in the chemical DNA sequencing technique of Maxam and Gilbert (1980).

\section{RESULTS}

\section{Identification of Putative $\delta$-Promoter Regulatory Elements by (DMS) DNA Footprinting}

We previously identified a 82 -bp sequence of the rat $\delta$-subunit gene that contains all the elements necessary for muscle developmental stage specific expression (Chahine et al., 1992). In order to identify potential regulatory elements residing within this piece of DNA we used a DNA footprinting procedure that employs DMS as a chemical probe for regions of DNA bound by protein. DMS chemically modifies DNA by methylating guanine residues and subsequent treatment with piperidine causes chemical strand scission at the modified residues. Therefore, only the interactions of protein factors with guanine residues can be observed using this method. Protein factors binding to DNA sequences can have two effects on modifying DMS methylation patterns. One effect is that of protection from DMS methylation, while the other is that of hypermethylation due to the creation of hydrophobic pockets near the affected residues.

Incubation of the DNA probe with myotube nuclear extract identified a number of residues that were either protected from DMS methylation or hypermethylated (Fig. 1). Many of these residues appear to reside within consensus sequences comprising known transcription factor binding sites. These sites include an E-box sequence (CACCTG) 


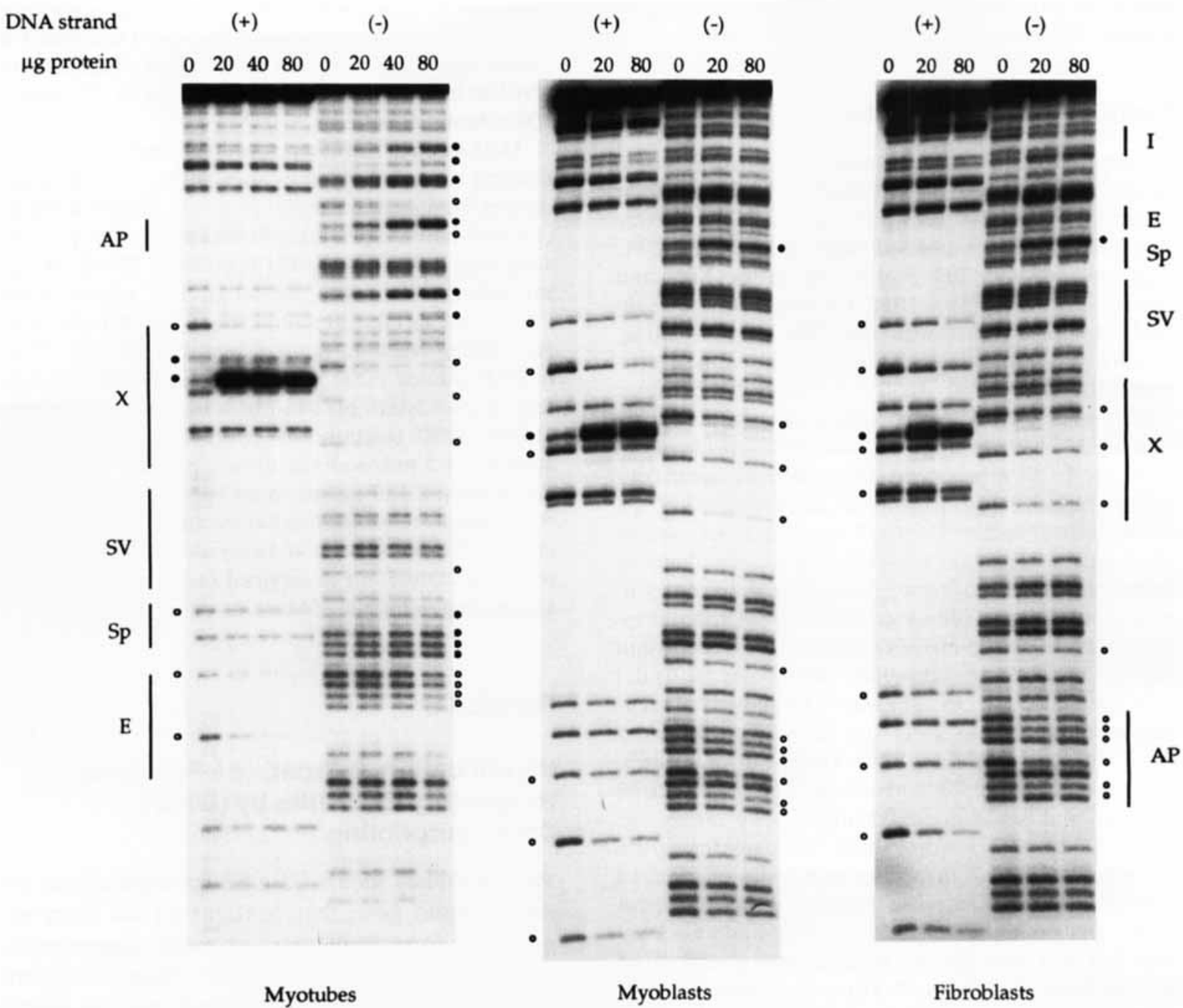

Figure 1 DMS footprinting identifies putative regulatory elements in the $\delta$-subunit gene's 5' flanking DNA. Results from DMS footprinting analysis of the 102-bp $\delta$-promoter region using partially purified nuclear extracts from either $\mathrm{C} 2 \mathrm{C} 12$ myotubes, myoblasts, or NIH3T3 cells is shown. Binding to both the coding ( + ) and noncoding strand ( - ) are shown. Regions containing guanine residues that were protected $(O)$ or hypermethylated $(\bullet)$ are indicated with lines and labeled along the side. Note that gels showing myoblasts and fibroblasts results were run slightly longer than that showing myotube results. AP, putative AP2 element; X, enhancer X region; SV, SV40 core enhancerlike sequence; Sp, Sp1-like element; E, E-box sequence; and I, initiator sequence.

centered $20 \mathrm{bp}$ upstream of the transcription start site ( $\mathrm{nt}-20$ ); an Sp1-like sequence (GCCGCC) located at $\mathrm{nt}-27$; a sequence similar to the SV40 core enhancer (SVCE) (CTTTCCAAACCCCT) (Khoury and Gruss, 1983) at $\mathrm{nt}-40$; a region bearing no similarity to any recognizable transcription factor binding sequence from $\mathrm{nt}-50$ to $\mathrm{nt}-70$, referred to as enhancer $\mathrm{X}$; an $\mathrm{AP} 2$ element (CCCCACCC) at $\mathrm{nt}-95$; and an initiator sequence (Smale and Baltimore, 1989) centered at nt -1 (Fig. 2).
Comparison of the methylation interference pattern between myotubes, myoblasts, and fibroblasts identifies some potentially important differences in protein binding (summarized in Fig. 2). First, we were not able to observe myotube-dependent protection of the $3 \mathrm{G}$ residues of the E-box in the (-) strand when myoblast or fibroblast nuclear extracts were used in the assay. Second although myoblast and fibroblast extracts caused a hypermethylation of a $\mathrm{G}$ residue in the $\mathrm{Sp} 1$-like sequence on the (-) strand, they do not cause protection of 
A.

MYOTUBES

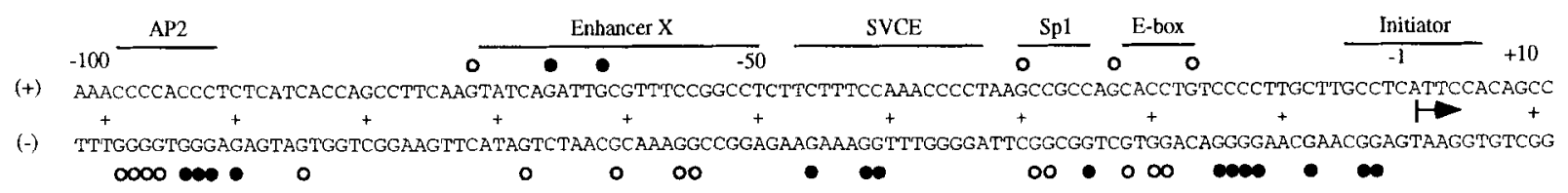

B.

FIBROBLASTS/MYOBLASTS

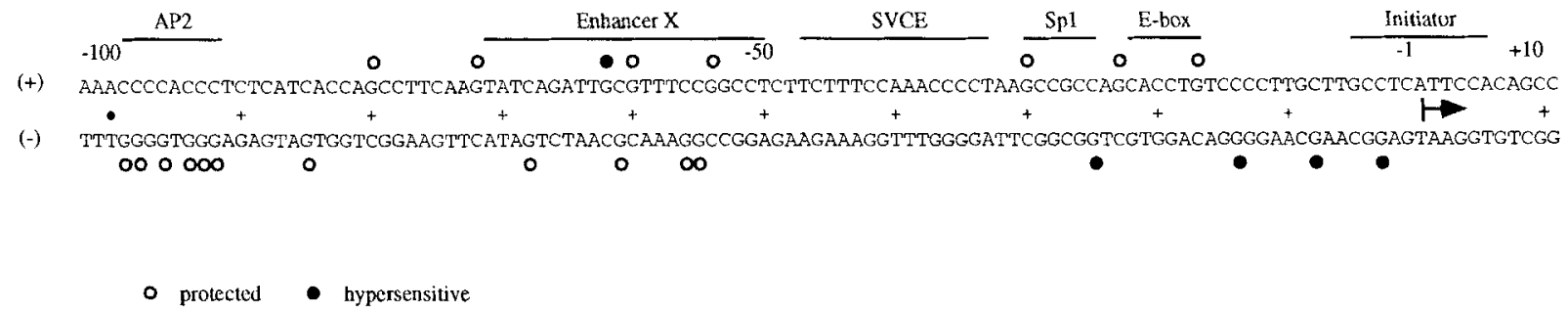

Figure 2 Summary of footprinting analysis using nuclear extracts from $\mathrm{C} 2 \mathrm{C} 12$ myotube and NIH3T3 cells. The DNA sequence of the $\delta$-subunit gene's $5^{\prime}$ flanking DNA extending from nucleotides -102 to +11 relative to the transcriptional start site (arrow) is shown for both the coding $(+)$ and noncoding (-) strands. (A) Summary of footprinting data using myotube nuclear extracts. (B) Summary of footprinting data using myoblast/NIH3T3 cell nuclear extracts. Interactions of nuclear factors are indicated by circles above or below the sequence. Closed circles indicate hypersensitive residues while open circles represent protected residues. Lines and identifiers above the sequences are putative binding sites for nuclear factors described in the text.

the two other $\mathrm{G}$ residues that are observed with myotube extracts. Third, the hypersensitive sites, observed in the SV region of the (-) strand using myotube nuclear extracts, are not hypermethylated when myoblast or fibroblast extracts are employed. Fourth, the AP region of the (-) strand is both hypermethylated and protected when myotube extracts are used, while only protections are observed when myoblast and fibroblast extracts are used in the methylation interference assay. In general, nuclear extracts derived from myoblasts and fibroblasts generated similar methylation interference patterns, suggesting similar proteins from these two cell types may be interacting with the DNA. In contrast, a significantly different pattern was generated when myotube nuclear extracts were employed, suggesting that myotube-specific factors mediate this specificity. Figure 2 summarizes the methylation interference patterns generated using these various extracts.

\section{Multiple Elements within 82-bp $\delta$ Promoter Are Necessary for Expression in Myotubes and Repression in Fibroblasts}

We previously identified a small piece of $\delta$-promoter DNA extending 82 nucleotides upstream of the transcriptional start site that retained a musclespecific expression profile (Chahine et al., 1992). This fragment lacks a putative AP2 element that is necessary for maximal $\delta$-promoter activity (Chahine et al., 1992). In order to identify sequences within this 82-bp promoter fragment that are necessary for muscle-specific expression, we created several internal deletions and mutations. Scannerlinker mutations were made in which $17 \mathrm{bp}$ of sequence from within the $\delta 82$-bp region was deleted and replaced by 17 bp of linker DNA. To insure that specific effects were not contributed by the introduced linker, experiments were repeated in con- 


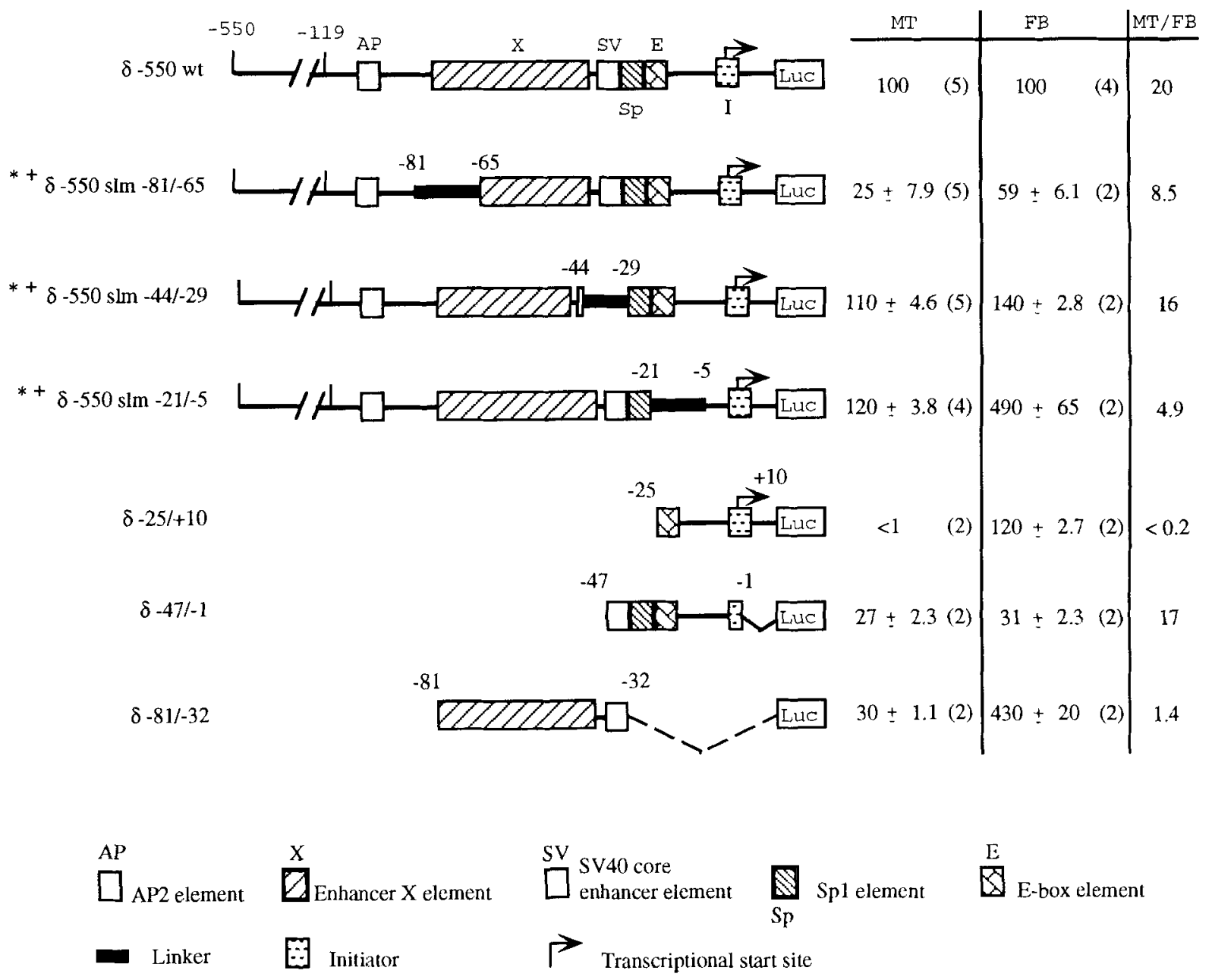

Figure 3 Identification of $\delta$-promoter sequences mediating muscle-specific expression. Various scanner-linker mutations and deletions are represented schematically, with the numbers indicating the sequences replaced, deleted, or present. These expression vectors were cotransfected with SV2CAT into C2C12 myotubes (MT) or NIH3T3 fibroblasts (FB). After $48 \mathrm{~h}$ cells were harvested and luciferase and CAT activities were determined. Results are shown with standard deviations on the right-hand side of the figure. Values are reported as a percentage of $\delta$-550 wt expression in myotubes (MT) or fibroblasts (FB). In addition the ratio of expression myotubes / fibrolasts (MT/FB) is provided. Numbers in parenthesis indicate the number of times each experiment was performed. Each experiment consisted of three replicas. (*) These clones were also tested in primary myotubes with similar results, with the exception of the Ebox mutation ( $\delta-550 \mathrm{slm}-21 /-5)$, which showed only $60 \%$ activity as compared to the wildtype promoter. $(+)$ These scanner linker mutations with $5^{\prime}$ ends at -119 instead of -550 showed similar results. Boxes and rectangles representing putative regulatory elements are shown to help identify DNA regions containing mutations and are not necessarily drawn to scale.

structs in which the linker was removed. Similar results were obtained regardless of the presence or absence of linker. The different deletion and mutation constructs and their expression in myotubes and fibroblasts are indicated in Figure 3.

A scanner linker mutation residing in the enhancer $X$ element (which spans nt -70 to -50 based on footprinting and expression assays) sig- nificantly reduced promoter activity in both myotubes and fibroblasts (clone $\delta-550 \mathrm{slm}-81 /-65$; Fig. 3). In contrast, deletion or mutation of DNA containing the E-box element (clones $\delta-550 \mathrm{slm}$ $-21 /-5$ and $\delta-81 /-32$; Fig. 3 ) consistently resulted in increased promoter activity in fibroblasts (Fig. 3). Both these results are consistent with mutational analysis of similar regions of the mouse $\delta$ 
promoter (Simon and Burden, 1993). However, unlike that found for the mouse promoter (Simon and Burden, 1993; W.W. and D.G. unpub. observ.), E-box mutations in the rat promoter had little effect on expression in the myotubes $(\delta-550$ $\operatorname{sim}-21 /-5$ in Fig. 3). This latter effect was not a result of incomplete cell differentiation or stability of the reporter gene because time course experiments using the human growth hormone reporter gene gave similar results (W.W. and D.G., unpub. oberv.).

Of the scanner-linker mutations shown in Figure $3, \delta-550 \mathrm{slm}-21 /-5$, which eliminates the E-box sequence and $3^{\prime}$ flanking DNA, showed the most dramatic effect on muscle-specific expression, suggesting that the E-box is necessary for this expression profile. However, this region of DNA on its own is insufficient in directing muscle-specific expression, yet expresses at near wild-type levels in fibroblasts $(\delta-25 /+10 ;$ Fig. 3$)$. In contrast, $\delta-47 /$ -1 does contain muscle-specific promoter activity, suggesting muscle specificity results from multiple elements within this region of DNA. Finally, sequences spanning residues -81 thru -32 , although containing promoter activity, do not confer a muscle-specific expression profile $(\delta-81 /-32$; Fig. 3$)$. The increased level of expression of $\delta-81 /-32$ in fibroblasts is consistent with other constructs lacking an E-box $(\delta-550 \mathrm{slm}-21 / 5$ in Fig. 3). It should be noted that constructs $\delta-47 /-1$ and $\delta$ $-82 /-32$ lack a complete initiator sequence that is believed to be important for transcript initiation, and therefore makes interpretation of the above results difficult. In order to verify that these sequences are able to regulate promoter activity, we created chimeric promoters containing these sequences in front of the minimal enkephalin promoter ( see below and Fig. 4).

\section{Identification of a General and a Muscle- Specific Enhancer within 82-bp $\delta$-Subunit Promoter}

The above described mutations along with the DNA footprinting studies identified important regulatory regions of the $\delta$ promoter. Many of these mutations appeared to modestly contribute to muscle specific expression (Fig. 3), perhaps suggesting multiple redundant elements. However, deletion of DNA from the $5^{\prime}$ end of this promoter suggested that one set of elements conferring muscle specificity resided within the first 47 bp of the $\delta$ pro$\operatorname{moter}(\delta-47 /-1 ;$ Fig. 3$)$. To determine if this and any other regions functioned as muscle-specific en- hancers, we placed various fragments from the $\delta$ promoter in front of a minimal enkephalin promoter (MEK) driving luciferase expression. These constructs were then transfected into both $\mathrm{C} 2 \mathrm{C} 12$ myotubes and NIH3T3 cells. Results of these experiments are shown in Figure 4. Expression is represented as a percentage relative to the minimal enkephalin promoter. Also shown is the myoblast/ fibroblast expression ratio. This analysis revealed two regions that are able to enhance expression from the minimal enkephalin promoter.

The region from $\mathrm{nt}-81$ to $\mathrm{nt}-32$, containing DNA labeled as enhancer $X$ and SVCE, functions as an enhancer in both muscle and fibroblast cells increasing expression by 9.5-fold and 14-fold above MEK expression in each cell type, respectively (clone $\delta-81 /-32$ MEK; Fig. 4). This region also functioned in the reverse orientation, although to a slightly lesser extent, increasing expression by 7.2-fold in muscle and 3.9-fold in fibroblast like cells (clone $\delta-32 /-81$ MEK; Fig. 4).

Interestingly, the region spanning nucleotides -47 to -1 , which contains putative E-box, Sp1like, and SVCE elements, functions as a strong muscle-specific enhancer. This region of DNA increases the MEK promoter activity about 26-fold in muscle cells, while only increasing it 1.4-fold in fibroblasts (clone $\delta-47 /-1$ MEK; Fig. 4). This muscle-specific expression is retained when this same region is used in the reverse orientation except that the enhancement in muscle is smaller at 7.1-fold (clone $\delta-1 /-47$ MEK; Fig. 4).

The region spanning nucleotides -106 to -72 contains a putative AP2 site (CCCCACCC) but exhibits little if any enhancement in myotubes and only a two fold enhancement in fibroblasts (clone $\delta-106 /-72$ MEK; Fig. 4). Previous deletion analysis, however, showed this region to be important for promoter activity (Chahine et al., 1992).

Surprisingly, the region between $\mathrm{nt}-25$ and $\mathrm{nt}$ +10 , which spans the E-box and initiator sequence, is not sufficient to confer any enhancement or muscle specificity on MEK promoter activity (clone $\delta$ $-25 /+10$ MEK; Fig. 4). In addition, experiments using concatamers of three oligos containing the SVCE-like sequence exhibited no enhancer activity as well (data not shown). Finally, enhancer experiments using a minimal muscle creatine kinase promoter were also performed with similar results, indicating that these enhancer effects are not solely limited to the MEK promoter (data not shown).

Previous experiments, mapping the transcriptional start site, confirmed that the $\delta$-promoter enhancer sequences conferred increased activity on the 


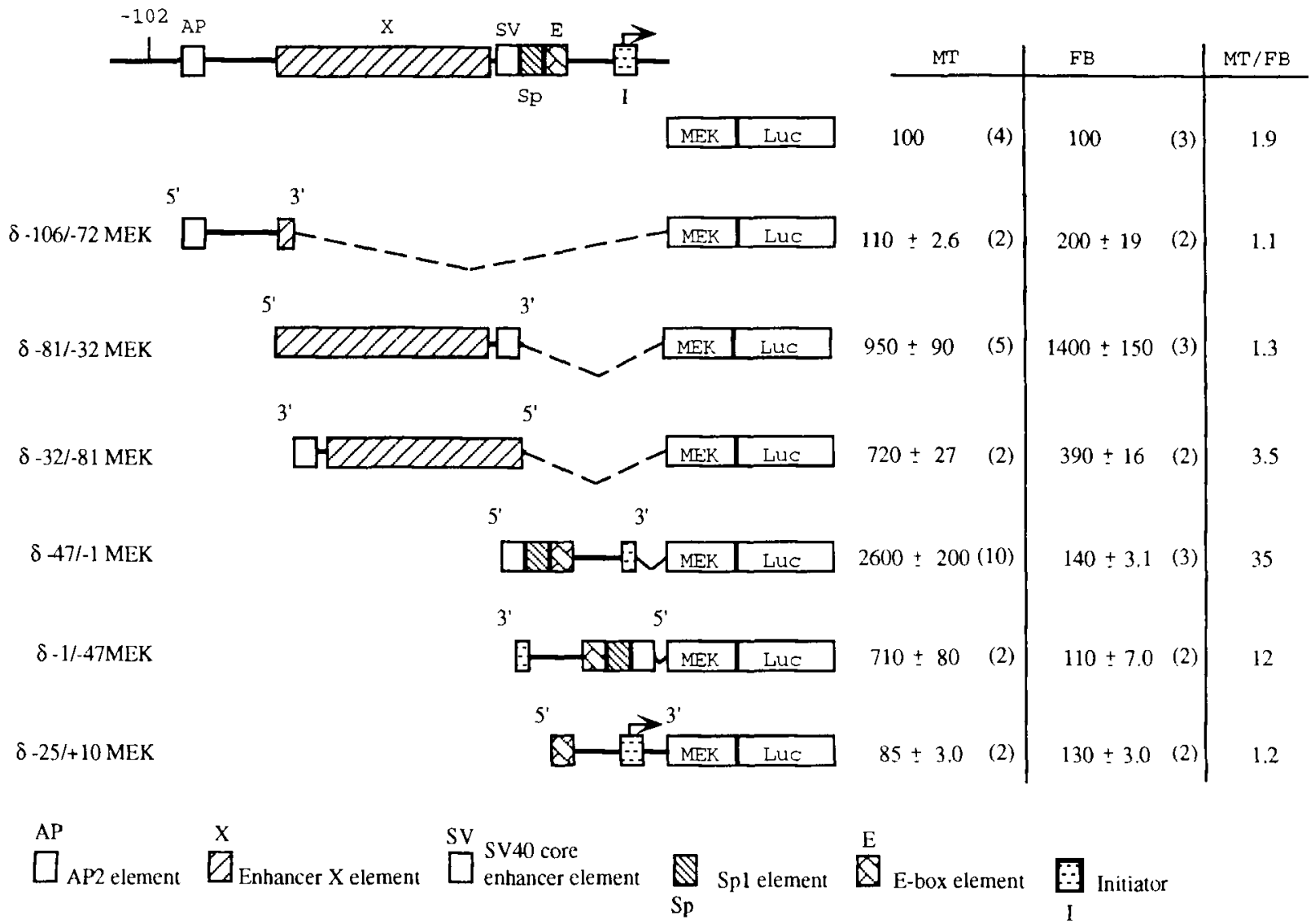

Figure 4 Identification of a 47-bp muscle-specific enhancer from the $\mathrm{nAChR} \delta$-subunit gene promoter. Diagram at the top of the figure shows the 102-bp $\delta$-promoter region with putative regulatory elements. based on DMS footprinting and expression assays, indicated by boxes and rectangles. Below this are diagrams of the various constructs containing fragments of the $\delta$ promoter subcloned in front of a minimal enkephalin (MEK) promoter driving luciferase ( Luc) expression. These constructs were transfected into $\mathrm{C} 2 \mathrm{C} 12$ myotubes (MT) or NIH3T3 fibroblastlike cells (FB), and their level of expression was determined and reported as a percentage of that found for the MEKLuc construct (MEKpXP2) and as a ratio myoblasts/ fibroblast $(\mathrm{MB} / \mathrm{FB})$. Numbers in parentheses indicate the number of times each experiment was repeated. Each experiment was performed in triplicate. SV2CAT DNA was cotransfected with all constructs and results were normalized to its expression. Boxes and rectangles representing putative regulatory elements are shown to help identify these regulatory sequences within the various chimeric promoter constructs and are not necessarily drawn to scale.

MEK promoter (Walke et al., 1996). Even construct $\delta-25 /+10$ MEK showed initiation at the MEK promoter, with undetectable initiation within the $\delta$-promoter's initiator sequence (indicated by an arrow above the initiator sequence in Fig. 4).

\section{Site Directed Mutagenesis Identifies Sequences throughout 47-bp Enhancer that Are Necessary for Muscle-Specific Expression}

The mutation and deletion studies indicated that the E-box just upstream of the transcription start site was necessary for $\delta$-promoter repression in nonmuscle cells (Fig. 3); yet this E-box, along with downstream promoter sequences, was not sufficient to confer muscle-specific expression $(\delta-25 /$ +10 , Fig. 3 and $\delta-25 /+10$ MEK, Fig. 4). Therefore, additional elements are likely to be necessary for this expression pattern. The enhancer assays suggest that these additional elements reside within the 47 bp muscle-specific enhancer ( Fig. 4). Therefore, mutations were introduced into the enhancer, and their effect on muscle-specific expression was assayed in $\mathrm{C} 2 \mathrm{C} 12$ myotubes and fibroblasts (Fig. 5 ). Point mutations in all three of the indicated re- 


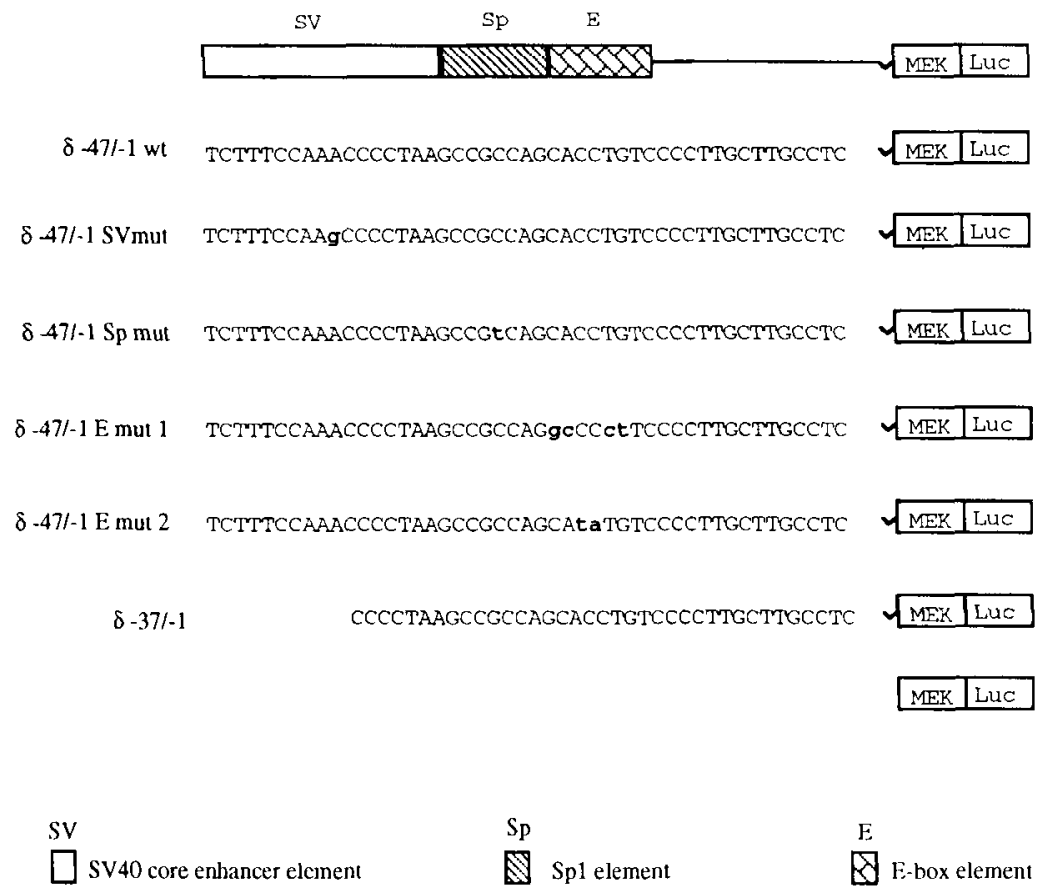

\begin{tabular}{|c|c|c|}
\hline MT & $\mathrm{FB}$ & $M T / F B$ \\
\hline 100 & 100 & 35 \\
\hline $15 \pm 6$ & $130 \pm 6 \quad(2)$ & 4.0 \\
\hline $18 \pm 6$ & $220 \pm 17$ (2) & 2.9 \\
\hline $15 \pm 6$ & $180 \pm 7 \quad(2)$ & 2.9 \\
\hline $8 \pm 2$ & $410 \pm 17$ & 0.68 \\
\hline $34 \pm 9(3)$ & $140 \pm 7 \quad(2)$ & 8.5 \\
\hline $4.2 \pm 1$ (3) & $90+17(2)$ & 1.6 \\
\hline
\end{tabular}

Figure 5 Site-directed mutagenesis identifies sequences in the muscle-specific enhancer that are necessary to confer muscle-specific enhancement onto a heterologous promoter. Diagrammed are the wild-type and various mutant constructs used in these studies. Top diagram shows putative regulatory regions of the $\delta$-muscle specific enhancer. Below this are shown the DNA sequences of the wild type and various mutations. Mutations are shown in bold and lower case type. $\delta$-Enhancer MEK Luc constructs were cotransfected with SV2CAT into C2C12 myotubes (MT) or NIH3T3 fibroblast cells (FB) and assayed for luciferase and CAT activity $48 \mathrm{~h}$ posttransfection. Results are shown with standard deviations on the right-hand side of the figure. Values are represented as a percentage of wild-type expression and as a ratio of myotube/fibroblast. Experiments were performed in triplicate and results were normalized to SV2CAT expression. Numbers in parentheses indicate number of repetitions for each experiment.

gions led to a significant reduction in the musclespecific enhancer effect, while mutations in the Spl-like and E-box sequence also caused increased expression in fibroblast cells. Thus all of these elements of $\delta-47 /-1$ appear to be necessary for generating a muscle-specific enhancer. Interestingly, $\delta$ $-47 /-1$ E mut 2 is not able to confer muscle-specific expression onto the MEK promoter, even though the mutation did not eliminate the E-box, but merely changed its central, variable nucleotides. This result suggests that the type of E-box embedded in the 47-bp enhancer is critical to its function.

\section{DISCUSSION}

Our experiments identified a 47-bp sequence just upstream of the nAChR $\delta$-subunit gene's transcrip- tional start site that can function as a muscle-specific enhancer (Fig. 4). This enhancer contains three putative elements. The most 5 ' element has similarity to the SV 40 core enhancer (Khoury and Gruss, 1983), which is followed by an Spl-like sequence and an E-box. All three of these sequences are necessary for muscle-specific expression, because point mutations introduced into any of them abrogated muscle-specific expression ( Fig. 5).

The combinatorial action of multiple discreet elements functioning as a muscle-specific enhancer is not unique to the nAChR $\delta$-subunit gene. Cooperation between MyoD family members and other factors was previously proposed to mediate muscle-specific expression of a number of muscle genes (Sartorelli et al., 1990; Lin et al., 1991; Bessereau et al., 1993; Li and Capetanaki, 1994). For example, the muscle-specific expression of the troponin 1 gene is mediated by an enhancer located in the 
first intron (Lin et al., 1991). This enhancer contains three protein binding sites, one of which is an E-box and binds MyoD family members. However, for full muscle-specific enhancer activity two other binding sites are required that bind proteins expressed in muscle and nonmuscle cells. Likewise, muscle-specific expression of the nAChR $\alpha$ subunit gene appears to require interactions between myogenic factors SP1 and GBF (Bessereau et al., 1993). These putative multiprotein complexes that form on the enhancer may facilitate interactions with the basal transcriptional machinery ultimately leading to increased promoter activity.

Within the rat $\delta$-subunit gene's 47-bp enhancer resides an E-box sequence that was previously shown to be necessary for muscle-specific expression of the mouse $\delta$-subunit gene ( Simon and Burden, 1993). In that study it was suggested that nucleotides immediately flanking this E-box or its relationship to other elements such as enhancer X or the initiator sequence may determine its musclespecific properties. Our results with the rat gene suggest that the critical sequences determining muscle specificity reside within a 47-bp sequence that does not include enhancer $X$ or a complete initiator sequence. However, based on our mutational studies, we suspect that enhancer $X$ can participate in muscle-specific expression because mutation of this sequence decreased muscle-specific expression by about $50 \%(\delta-550 \mathrm{slm}-81 /-65$; Fig. 3$)$. In addition, this element may be able to compensate for mutations introduced into the SVCE and E-box regions as indicated by constructs $\delta-550 \mathrm{slm}-44$ / -29 and $\delta-550 \mathrm{slm}-21 /-5$ (Fig. 3 ). In these cases we found that a mutation in the SVCE or Ebox region, which abrogated muscle-specific expression in our enhancer assays (Fig. 5), had only a modest affect on myotube expression in the context of the $\delta$ promoter (Fig. 3). Multiple sequences with redundant activities is not uncommon as illustrated by the nAChR $\alpha$-subunit promoter whose Spl site can be replaced by an MEF2 site to activate muscle-specific enhancer activity (Bessereau et al., 1993). However, in our studies we could not rule out the possibility that these differences reflect the different types of mutations made in the enhancer versus $\delta$-promoter assays.

One motivation for characterizing muscle-specific expression of the $\mathrm{nAChR}$ subunit genes was that the mechanisms mediating their induction during development may be shared with those mediating their increase following cessation of muscle activity. Consistent with this idea is our recent finding that this same 47-bp muscle-specific en- hancer also functions as an activity-dependent enhancer conferring activity-dependent regulation onto a heterologous promoter (Walke et al., 1996). In addition, mutational studies of the mouse and chick nAChR promoters demonstrated that the same E-boxes are necessary for muscle-specific and activity-dependent expression (Bessereau et al., 1994; Tang et al., 1994; Su et al., 1995). Although these results indicate that the same DNA sequence can mediate muscle-specific and activity-dependent gene expression, it is not clear if similar proteins bind to these sequences under these different conditions. Future experiments will utilize the sequences reported here to begin identifying and characterizing their binding proteins.

This work was supported by grants from NINDS ( 2 RO1 NS2153-08), the Muscular Dystrophy Association, and the Lucille P. Markey Charitable Trust. W. W. was supported by an NRSA predoctoral fellowship from the NIMH ( 5 F31 MH10328-02). We thank Dr. A. F. Seasholtz for providing the enkephalin promoter and N. Goburdhun for technical assistance.

\section{REFERENCES}

BALDWIN, T. J. and BURDEN, S. J. ( 1988). Isolation and characterization of the mouse acetylcholine receptor $\delta$-subunit gene: identification of a 148-bp cis-acting region that confers myotube-specific expression. $J$. Cell Biol. 107:227 I-2279.

Berberich, C., Durr, I., Koenen, M., and WitzeMANN, V. (1993). Two adjacent E box elements and a M-CAT box are involved in the muscle-specific regulation of the rat acetylcholine receptor $\beta$-subunit gene. Eur. J. Biochem. 216:395-404.

Bessereau, J. L., Mendelzon, D., LePoupon, C., Fiszman, M., Changeux, J. P., and Piette, J. (1993). Muscle-specific expression of the acetylcholine receptor $\alpha$-subunit gene requires both positive and negative interactions between myogenic factors, $\mathrm{Spl}$ and GBF factors. EMBO J. 12:443-449.

Bessereau, J. L., Stratford-Perricaudet, L. D., Piette, J., LePoupon, C., and Changeux, J.-P. (1994). In vivo and in vitro analysis of electrical activity-dependent expression of muscle acetylcholine receptor genes using adenovirus. Proc. Natl. Acad. Sci. USA 91:1304-1308.

Bevan, S. and SteinbaCh, J. H. (1977). The distribution of $\alpha$-bungarotoxin binding sites on mammalian skeletal muscle developing in vivo. J. Physiol. 267: 195-215.

Brasier, A. R., TAte, J. E., and HABENER, J. F. ( 1989 ). Optimized use of the firefly assay as a reporter gene in mammalian cell lines. BioTechniques 7:1116-1122. 
Buonanno, A. and J. P. Merlie, J. P. (1986). Transcriptional regulation of nicotinic acetylcholine receptor genes during muscle development. J. Biol. Chem. 261:11452-11455.

Chahine, K. G., Walke, W., and Goldman, D. (1992). A 102 base pair sequence of the nicotinic acetylcholine receptor $\delta$-subunit gene confers regulation by muscle electrical activity. Development 115:213219.

Comb, M., Birnberg, N. C., Seasholtz, A., Herbert, E., and GOODMAN, H. M. (1986). A cyclic AMP- and phorbol ester-inducible DNA element. Nature 323: 353-356.

Dignam, J. D., Lebovitz, R. M., and Roeder, R. G. (1983). Accurate transcription initiation by RNA polymerase II in a soluable extract from isolated mammalian nuclei. Nucleic Acids Res. 11:1475-1489.

Hasty, P., Bradley, A., Morris, J. H., Edmondson, D. G., VENuti, J. M., Olson, E. N., and Klein, W. H. (1993). Muscle deficiency and neonatal death in mice with a targeted mutation in the myogenin gene. Nature 364:501-506.

KHOURY, G. and Gruss, P. (1983). Enhancer elements [minireview]. Cell 33:313-314.

LI, H. and Capetanaki, Y. (1994). An E box in the desmin promoter cooperates with the $\mathrm{E}$ box and $\mathrm{MEF}$ 2 sites of a distal enhancer to direct muscle-specific transcription. EMBO J. 13:3580-3589.

LIN, H., YUTZEY, K. E., and KONIECZNY, S. F. (1991). Muscle-specific expression of the troponin I gene requires interactions between helix-loop-helix muscle regulatory factors and ubiquitous transcription factors. Mol. Cell. Biol. 11:267-280.

Maxam, A. M. and Gilbert, W. (1980). Sequencing end-labeled DNA with base-specific chemical cleavages. Methods Enzymol. 65:499-559.

Neumann, J. R., Morency, C. A., and Russian, K. O. (1987). A novel rapid assay for chloramphenicol acetyltransferase gene expression. BioTechniques 5:444-447.

NORDEEN, S. K. (1988). Luciferase reporter gene vectors for analysis of promoters and enhancers. BioTechniques 6:454-457.

Numberger, M., Durr, I., Kues, W., Koenen, M., and WITZEMANN, V. (1991). Different mechanisms regulate muscle-specific AChR $\gamma$ - and $\varepsilon$-subunit gene expression. EMBO J. 10:2957-2964.

Piette, J., Bessereau, J. L., Huchet, M., and
ChangeuX, J. P. ( 1990). Two adjacent MyoD l-binding sites regulate expression of the acetylcholine receptor $\alpha$-subunit gene. Nature 345:353-355.

Prody, C. A. and Merlie, J. P. ( 1991 ). A developmental and tissue-specific enhancer in the mouse skeletal muscle acetylcholine receptor $\alpha$-subunit gene regulated by myogenic factors. J. Biol. Chem. 266:2258822596.

SARtorelli, V., Webster, K. A., and Kedes, L. (1990). Muscle-specific expression of the cardiac a-actin gene requires MyoD1, CArG-box binding factor and Spl. Genes Dev. 4:1811-1822.

Simon, A. M. and Burden, S. J. (1993). An E-box mediates activation and repression of the acetylcholine receptor $\delta$-subunit gene during myogenesis. $\mathrm{Mol}$. Cell. Biol. 13:5133-5140.

Smale, S. T. and Baltimore, D. (1989). The "initiator" as a transcriptional control element. Cell 57:103113.

Su, C.-T., HuanG, C.-F., and SCHMIDT, J. (1995). The depolarization response element in acetylcholine receptor genes is a dual-function E box. FEBS Lett. 366: 131-136.

TSAY, H.-J. and SCHMIDT, J. (1989). Skeletal muscle denervation activates acetylcholine receptor genes. $J$. Cell Biol. 108:1523-1526.

TANG, J., Jo, S. A., and Burden, S. J. (1994), Separate pathways for synapse-specific and electrical activitydependent gene expression in skeletal muscle. Development 120:1799-1804.

Walke, W., Staple, J., Adams, L., Gnegy, M., ChaHINE, K., and GOLDMAN, D. (1994). Calcium-dependent regulation of rat and chick muscle nicotinic acetylcholine receptor ( $\mathrm{nAChR}$ ) gene expression. J. Biol. Chem. 269:19447-19456

WALKE, W., XIAO, G., and GOLDMAN, D. (1996). Identification and characterization of a 47 base pair activity-dependent enhancer of the rat $\mathrm{nAChR} d$-subunit promoter. J. Neurosci., to appear.

WANG, Y., XU, H. P., WANG, X. M., BALlivet, M., and SCHMIDT, J. (1988). A cell type-specific enhancer drives expression of the chick muscle acetylcholine receptor $\alpha$-subunit gene. Neuron 1:527-534.

Wigler, M., Pellicer, A., Silverstein, S., Axel, R., URlaub, G., and Chasin, L. (1979). DNA-mediated transfer of the adenine phosphoribosyltransferase locus into mammalian cells. Proc. Natl. Acad. Sci. USA 76:1373-1376. 